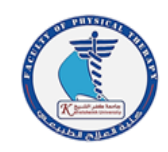

\title{
Ultrasound Versus Nerve Gliding on Hand Grip Strength in Cubital Tunnel Syndrome
}

\author{
Mohamed R. Gaber' ${ }^{1}$ Fatma S. Amin², Mohamed S. Eldein ${ }^{3}$, Sherif A. Khalid ${ }^{4 *}$ \\ ${ }^{1}$ B.SC of physical therapy, Faculty of physical therapy, Cairo University, Egypt. \\ 2 Professor of Physical Therapy, Basic Science Department, Faculty of Physical Therapy, Cairo \\ University, Egypt. \\ ${ }^{3}$ Associate Professor of Physical Therapy, Basic science Department, Faculty of Physical Therapy, \\ Cairo University, Egypt.
}

${ }^{4}$ Professor of orthopedic surgery, Faculty of Medicine, Cairo University, Egypt.

*Correspondence to
Mohamed R. Gaber
B.SC of Physical Therapy,
Faculty of Physical
Therapy, Cairo University,
Egypt.
Tel: 002-01117181630
Email;
Smartmind89@gmail.com

Published online:

March 2021

\begin{abstract}
:
Purpose: To compare the effect of ultrasound versus nerve gliding on hand grip strength in patients with cubital tunnel syndrome.

Methods: Forty patients suffering from cubital tunnel syndrome from out-clinic of faculty of physical therapy, Cairo university, were participated in this study. Their ages ranged from 40 to 60 years old from both sexes. They were assigned randomly into two equal groups; group (A) received ultrasound therapy, group (B) received nerve gliding technique, in addition to rigid night elbow splint for both groups, treatment was 3 sessions/week, for 6 weeks. Measurements of hand grip strength were recorded before and at the end of intervention.

Results: showed that there was significant improvement in hand grip strength for group B compared to group A.

Conclusion: Nerve gliding technique is more effective than ultrasound in improving hand grip strength in CuTS patients.

Key words: cubital tunnel syndrome; ultrasound therapy; nerve gliding technique; hand grip strength; night splint.
\end{abstract}

\section{Introduction}

Cubital tunnel syndrome (CuTS) is the most common type of ulnar nerve compression and frequent upper extremity entrapment neuropathy after carpal tunnel syndrome. It is the cause of considerable pain and disability for patient.

CuTS may have an insidious or acute onset. The clinical symptoms relate to the mixed sensory and motor fibers of this nerve in early disease. The patient has paresthesia that is usually related to motion and radiates distally to fifth finger and inner side of fourth finger. There may be discomfort and tenderness over the medial epicondyle, with proximal and distal elbow extension. Weakness of intrinsic hand muscles which supplied by ulnar nerve also may be observed in this period. Weakness begins with clumsiness and reduced hand strength, then progress to grip and pinch weakness. A sign of advanced motor loss is intrinsic muscles atrophy and clawing of ring and little fingers (1).

CuTS occur commonly in subjects whose work involves prolonged elbow flexion (as holding the phone). The risk of CuTS increased when elbow flexed and pressured against a hard surface due, at least in part, to an increase in intraneural pressure in this position. Furthermore, the form of the tunnel varies from an oval to an ellipse when flexing the elbow; and the flexion of the elbow decreases the channel by $55 \%$. Flexion of the elbow, extension of the wrist and abduction of the shoulder increase intraneural pressure by six times (2).

Conservative treatment for CuTS can be received and will be effective in case of mild and moderate symptoms (3). 
Dellon et al recorded that conservative therapy was beneficial in about $90 \%$ of patients with grade 1 and $38 \%$ of patients with grade 2 (4). The aim of conservative treatment when treating CuTS is to decrease the degree of external stress on the nerve and minimize flexion at the elbow joint. This can be done through alteration of the operation by patient education and splinting. For this condition, non-surgical therapy may be used as long as the patient wants, but 3 to 6 months may seem appropriate. Traditional non-surgical treatment consists of ergonomic changes, avoidance of aggravating motions or postures, night splints, nonsteroidal anti-inflammatory drugs, and effective modal physical and/or occupational therapy $(1,5)$. Nerve mobilization exercises are a routine in treating carpal tunnel and CuTS for many clinicians. Using these techniques varies from source to source and requires a solid knowledge of application and timing (6).

According to Lungand and Amadio, These interventions may help to delineate where the problem resides and enhance clinical outcomes if used correctly. The principle of nerve glide (excursion) plays an important part in the formulation of the treatment $(4,6)$.

More recently, the use of nerve gliding and electrical modalities, including laser and ultrasound therapy, has seen a significant influx of physiotherapy literature (7).

\section{Patients and Methods}

\subsection{Participants}

Forty patients (23 females and 17 males) with

CuTS were recruited from outpatient clinics of faculty of physical therapy of Cairo University. They were assigned randomly into two equal groups; the first group (A) was composed of 20 patients who received ultrasound treatment in addition to rigid elbow night splint for 6 weeks. The second group (B) was composed of 20 patients who received nerve gliding in addition to rigid elbow night splint for 6 weeks.

\subsection{Instrumentation:}

\subsubsection{Measurement equipment}

Hand held dynamometer HHD:

It is a portable measuring device which is used to test muscle function. It is ideal device for routine screening of grip strength. It is used to test handgrip strength of athletes participating in sports where hands are used for throwing, catching or lifting as tennis player, rock climbers and gymnasts, and to monitor strength training and rehabilitation improvements(8). Before examination, the examiner showed how the dynamometer handle should be used. They gave the same instructions for each trial. After the patient was placed with the hand dynamometer, the examiner instructed the patient to grip the handle as much as possible and hold this for 3-5 seconds With 15-20 seconds rest time between the measurements(9).

The patient was instructed to squeeze the dynamometer as hard as possible, in addition to verbal encouragement from examiner for hard squeeze during testing(10). Three consecutive measurements were taken, recording the Peak of the three grips. For several factors, the maximum value was taken instead of the average value; issues may occur due to muscle exhaustion (11), as well as the maximum value used to measure hand grip reliability (12), as well as the maximum method used by other researchers $(1,9)$.

\subsubsection{Therapeutic equipment}

Therapeutic ultrasound machine

\subsection{Procedures of the study:}

Instructions and details of the study were explained in detail for every patient before starting the initial assessment, and a written consent form was signed by each patient before starting. The participating patients were instructed to report any side effects during the treatment sessions.

\subsubsection{Therapeutic Procedures for groups $(A)$}

All patients in group (A) (20 CuTS patients ,8 males and 12 females) were treated with US therapy combined with rigid elbow night splint. Ultrasound applied for 5 minutes each session, three times a week for 6 weeks. The US machine was set at a frequency of $1 \mathrm{MHz}$, an intensity of $1.5 \mathrm{~W} / \mathrm{cm} 2$, in continuous mode(13). The transducer was placed over the medial aspect of elbow joint behind medial humeral epicondyle.

Waves of ultrasound penetrate the skin and through vibration and cavitation, leads to tissues deep local heating, reduce inflammation and decrease pain. This heating effect of us improves tissues circulation; result in relaxation of tissues, and helps reduce inflammation and local swelling. The increase in blood flow also delivers more nutrients and oxygen to tissues, eliminates cell waste, and aids healing(14). This therapy was done three times/ week for six consecutive weeks.

\subsubsection{Therapeutic Procedures for groups $(B)$}

All patients in group (B) (20 CuTS patients, 9 males and 11 females) were treated with nerve gliding technique combined with rigid elbow night splint.

Nerve gliding that aims to glide the nerve by alternating motions of at least 2 joints in which one movement loads the peripheral nervous system while 
the other movement loads the nervous system at the same time. This technique is thought to slide the ulnar nerve without having to strain the nerve. This process allows gliding to take place inside the nerve itself and between the surrounding tissues.

Begin with the patient supine. then apply wrist extension and supination of the forearm followed by flexion of the elbow (full range); then apply depression of the shoulder girdle. Maintain the position and apply lateral rotation and abduction to the shoulder. The patient's hand is above his or her ear in the final position with fingers pointing backwards(15).

This therapy was done three times/ week for six consecutive weeks.

\section{Data analysis}

Hand grip strength was measured by using hand held dynamometer before treatment and after cessation of the treatment program in both groups after 6 weeks of treatment. Collected data were fed into computer for the statistical analysis; descriptive statistics as mean, standard deviation, minimum and maximum were calculated for each group. The t-test was done to compare the mean difference of both groups' pre and post treatment and within each group.

\section{Results}

A total of 40 participants were included in this study, and were randomized for study intervention. Group A consisted of 20 participants who received us three times per week for 6 weeks in addition to night elbow splint. Group B consisted of 20 participants who received ulnar nerve gliding three times per week for 6 weeks in addition to night elbow splint. All participants completed the trial.

There was no significant difference between groups at baseline in the mean values of "Age in Years" as the value of $(t)$ equals $(0.177)$, and the P-value is more than (0.05) table (1).

Table (1): Comparison between groups for Age in years and BMI

\begin{tabular}{|c|c|c|c|c|c|}
\hline \multicolumn{2}{|c|}{$\begin{array}{c}\text { Group A } \\
\mathrm{n}=20\end{array}$} & \multicolumn{2}{|c|}{$\begin{array}{c}\text { Group B } \\
\mathrm{n}=20\end{array}$} & \multirow[b]{2}{*}{ T.value } & \multirow[b]{2}{*}{ P.value } \\
\hline $\begin{array}{c}\text { Mean } \\
(\mu \mathrm{g} / \mathrm{dl})\end{array}$ & $\pm \mathrm{SD}$ & $\begin{array}{c}\text { Mean } \\
(\mu \mathrm{g} / \mathrm{dl})\end{array}$ & $\pm \mathrm{SD}$ & & \\
\hline 50.55 & 3.316 & 50.75 & 3.823 & 0.177 & $\begin{array}{c}0.861 \\
\text { (NS) }\end{array}$ \\
\hline 29.65 & 3.183 & 29.95 & 3.284 & 0.293 & $\begin{array}{c}0.771 \\
\text { (NS) }\end{array}$ \\
\hline
\end{tabular}

SD: standard deviation, P: probability, NS: not-significant.

Also There is no statistically significant difference between the two groups at baseline in the mean values of "BMI" as the value of (t) equals (0.771), and the P-value is more than (0.05) table (1).
Within-group comparison revealed a significant increase in HGS in both groups post treatment compared with that pretreatment $(<0.001)$ (table 2$)$.

Table (2): Comparison within group for HGS

\begin{tabular}{lcccccc} 
& \multicolumn{2}{c}{ Before treatment } & \multicolumn{2}{c}{ After treatment } & & \\
\cline { 2 - 5 } & $\begin{array}{c}\text { Mean } \\
\text { (degrees) }\end{array}$ & $\pm \mathrm{SD}$ & $\begin{array}{c}\text { Mean } \\
\text { (degrees) }\end{array}$ & $\pm \mathrm{SD}$ & T.value & P.value \\
\hline Group & 18.40 & 6.549 & 21.85 & 6.00 & 10.031 & 0.001 \\
A & & & & 2 & & $(\mathrm{~S})$ \\
Group & 19.75 & 6.67 & 25.85 & 7.213 & 17.967 & 0.001 \\
B & & 2 & & & & $($ HS $)$ \\
\hline S = Significant & & & HS = Highly Significant
\end{tabular}

Between groups comparison pretreatment revealed a no significant difference in HGS values ( $p>0.05$ ). Comparison between groups post treatment revealed that there was a significant increase in HGS values of group B compared with that of group A $(\mathrm{p}<0.05)$ (table 3)(fig 1).

Table (3): Comparison between groups for HGS

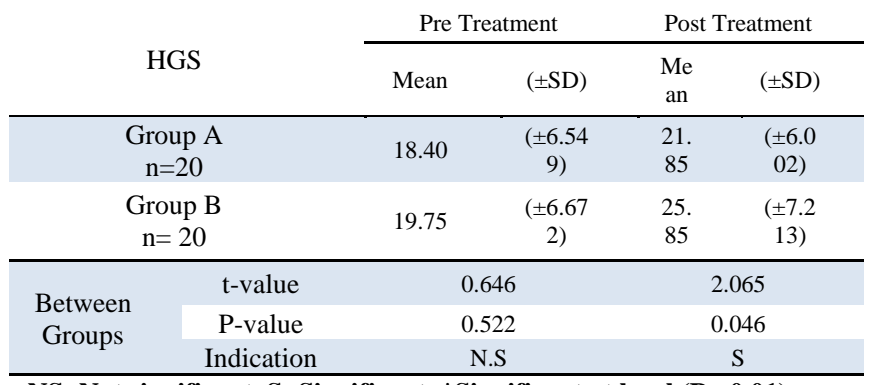

NS: Not significant, S: Significant. *Significant at level $(\mathrm{P}<0.01)$

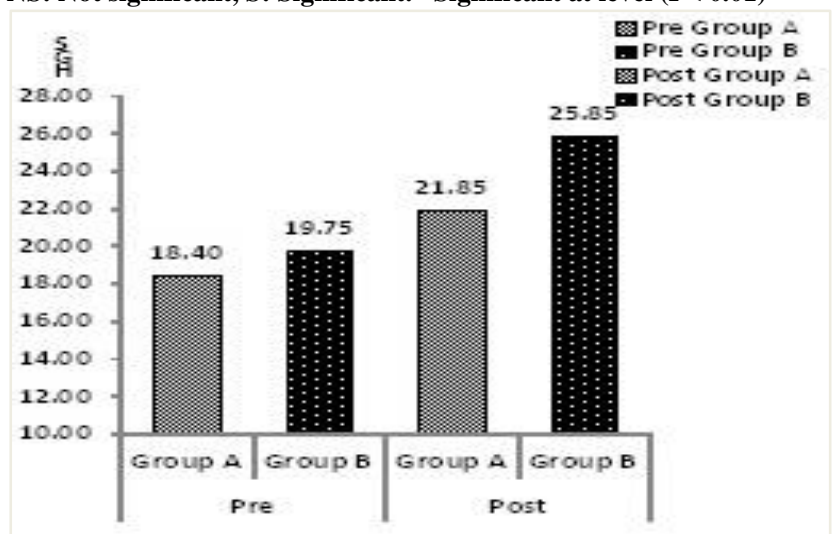

Figure (1) HGS Mean for groups A and B

\section{Discussion}

According to the results of this study, in patients having CuTS, nerve gliding group showed more significant improvement in hand grip strength as compared to ultrasound group assessed through HHD before and after treatment. Consequently; the results suggested a rejection of our hypothesis which stated that Nerve gliding has no more effect than ultrasound on hand grip strength in patients suffering from cubital tunnel syndrome.

Our subjects had lower grip strength compared to normative data. Both males and females hand grip 
strength increased following 6 weeks of treatment/splinting. Although the patients with CuTS continued to have significant deficits in strength in comparison to the norm, the differences in their strength was much less and trended towards small to moderate deficits instead of large deficits. Although previous researches on splinting usually report reduction of symptoms, not all have recorded improvements in hand strength, indicating that reduction of symptoms alone is not sufficient to explain improved strength. Our study included two treatment regimens along with the splinting. None of our regimens had a strengthening component, which begs the question: if we were not actively strengthening the muscle, how did muscle strength significantly improve, particularly as symptom reduction alone may not be enough to significantly affect strength? One possible explanation relates to our treatment programs.

Regarding to results of ultrasound group our findings had come in agreement with Michlovitz that provide data about effect of US on nerve conduction in normal nervous tissue and healing in damaged nerves(16). In the literature, US has been studied in the area of peripheral nerve compression, showing reduced pain and improved function with entrapment neuropathies; and it can facilitate regeneration resulting in better function and strength. Our study has been showed that hand grip strength was improved in ultrasound group post treatment than pretreatment $(22.55 \%)$.

Concerning the results of nerve gliding group, the results of our study come in agreement with Kleinrensik et al, who state that nerve gliding technique used for neural mobilization of the ulnar nerve to improve the condition of the upper limb muscles in CuTS. The concept of nerve gliding plays a key role in in the formulation of a nerve mobilization treatment plan. By pulling on both ends of the nerve, stress causes strain within the nerve. This effect reduces the vascular and axoplastic flow. Gliding means placing nerve tension at one point while removing it at another point. Gliding can take place within the nerve itself and can occur between the nerve and surrounding tissues (17).

According to data analysis in our study, the results of nerve gliding group revealed that there was a significant improvement in post treatment hand grip strength. The results of this study come in agreement with Wright et al, who reported that gliding of the nerve accumulates intraneural and extra neural fluids that may regulate the increased pressure caused by intraneural edema and fibroblastic activity. After removing the pressure, blood flow and axonal transport necessary for the functional and structural integrity of the neuron will recover resulting in better function of the nerve so better function of supplied muscles.

In our study, use of elbow night splint was supported from Calfee et al.who state that Splinting is meant to alleviate symptoms and prevent the progressive dysfunction of nerves. There are two issues that should bear consideration: the ability of the splint to maintain the elbow at the ideal amount of flexion and patient compliance with night splinting.

Ultimately the study proved that we can improve hand grip strength in grade 1 and grade 2 CuTS patients through conservative methods without surgical intervention.

\section{Conclusion}

Nerve gliding has a flavor effect than ultrasound on hand grip strength in patients suffering from cubital tunnel syndrome.

\section{Recommendation}

Studying the long effect of ulnar nerve gliding on cubital tunnel syndrome

Further studies should be conducted over increased treatment period.

\section{Conflict of Interests}

The authors declare no conflict of interest.

\section{References}

1. Robertson C, Saratsiotis J: A review of compressive ulnarneuropathy at the elbow. J Manipulative Physiol Ther 2005;28:345.

2. Cutts S. Cubital tunnel syndrome : Postgrad Med J 2007;83:28-31.

3. Butler DS. The sensitive nervous system. Unley, Australia:Noigroup Publications; 2000. p. 431.

4. Dellon AL. Review of treatment results for ulnar nerve entrapment at the elbow. J Hand Surg (Am) 1989;14:688-700.

5. Coppieters WM, Bartholomeeusen EK, Stappaerts HK: Incorporating nervegliding techniques in the conservative treatment of cubital tunnel syndrome. J Manipulative PhysiolTher 2004;27:5608.

6. Lund AT, Amadio PC: Treatment of cubital tunnel syndrome: perspective for the therapist. J Hand Ther 2006; 19:17080.

7. Carmen, JC; Roeder, BL; Nelson, JL; Beckstead, BL; Runyan, CM; Schaalje, GB; Robison, RA; Pitt, WG (2004). 
"Ultrasonically enhanced vancomycin activity against Staphylococcus epidermidis biofilms in vivo". Journal of biomaterials applications. 18 (4): 23745.

8. Holmich, P., Holmich, L R., \& Bjerg, A M: Clinical examination of athletes with groin pain: an intraobserver and interobserver reliability study. $\mathrm{Br} \quad \mathrm{J}$ Sports Med 2004: 38: 446-451.

9. Tsang, R.C.C. (2005). Reference values for 6-minute walk test and hand-grip strength in Healthy hong Kong Chinese adults. HKPJ, 23(1), 6-12.

10. Richards, L.G. (1997). Posture effects on grip strength. Arch Phys Med Rehabil, 78(10), 1154-6.

11. Haidar, S.G., Kumar, D., Bassi, R.S., \& Deshmukh, S.C. (2004). Average Versus Maximum Grip Strength: Which is More Consistent? J Hand Surg Br, 29(1), 8284.

12. Gerodimos, V. (2012). Reliability of Handgrip Strength Test in Basketball Players. J Hum Kinet, 31, 25-36.

13. Ozkan FU1, Saygı EK, Senol S, Kapcı S, Aydeniz B, Aktaş İ, Gozke E: New treatment alternatives in the ulnar neuropathy at the elbow: ultrasound and low-level laser therapy 2015 Sep;115(3):355-60.

14. Miller DL, Smith NB, Bailey MR, Czarnota GJ, Hynynen K, et al. (2012) Overview of therapeutic ultrasound applications and safety considerations. $\mathbf{J}$ Ultrasound Med 31: 623-634.

15. Rempel D, Dahlin L, Lundborg G. Pathophysiology of nerve compression syndromes: response of peripheral nerve to loading. J Bone Joint Surg Am 1999;81:1600-10.

16. Michlovitz SL. Is there a role for ultrasound and electrical stimulation following injury to tendon and nerve? J Hand Ther2005;18:292-7.

17. Kleinrensik GJ, Stoeckart R, Mulder P. Upper limb tension test as tools in the diagnosis of the nerve and plexus lesions: anatomical and biomechanical aspects. Clin Biomech 2000;15:9-15. 